\title{
One hour post-load plasma glucose and 3 year risk of worsening fasting and 2 hour glucose tolerance in the RISC cohort
}

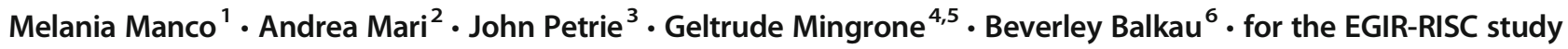 \\ group
}

Received: 3 September 2018 / Accepted: 22 November 2018 / Published online: 29 December 2018

(C) The Author(s) 2018

Keywords Diagnostic criteria $\cdot$ Post-challenge glucose $\cdot$ Post-load glucose $\cdot$ Prediabetes $\cdot$ Prediabetes phenotype $\cdot$ Progression

$\begin{array}{ll}\text { Abbreviations } \\ \text { BCGS } & \text { Beta cell glucose sensitivity } \\ \text { EGIR } & \text { European Group for the Study of Insulin Resistance } \\ \text { FPG } & \text { Fasting plasma glucose } \\ \text { IFG } & \text { Impaired fasting glucose } \\ \text { IGT } & \text { Impaired glucose tolerance } \\ \text { NGT } & \text { Normal glucose tolerance } \\ \text { OGIS } & \text { Oral glucose insulin sensitivity } \\ \text { 1hPG } & 1 \text { h post-load plasma glucose } \\ \text { 2hPG } & 2 \text { h post-load plasma glucose } \\ \text { RISC } & \text { Relationship between Insulin Sensitivity and } \\ & \text { Cardiovascular Risk }\end{array}$

Electronic supplementary material The online version of this article (https://doi.org/10.1007/s00125-018-4798-5) contains peer-reviewed but unedited supplementary material, which is available to authorised users.

Melania Manco

melania.manco@opbg.net

John Petrie

john.petrie@glasgow.ac.uk

1 Research Area for Multifactorial Diseases and Complex Phenotypes, Bambino Gesù Children's Hospital, Viale Ferdinando Baldelli 38, 00146 Rome, Italy

2 CNR Institute of Neuroscience, Padua, Italy

3 Institute of Cardiovascular and Medical Sciences, BHF Glasgow Cardiovascular Research Centre, University of Glasgow, 126 University Place, Glasgow G12 8TA, UK

4 Department of Internal Medicine, IRCCS Policlinico Universitario A. Gemelli, Catholic University of Sacred Heart, Rome, Italy

5 Department of Diabetes, King's College London, London, UK

6 CESP Centre for Research in Epidemiology and Population Health, Univ Paris-Saclay, Univ Paris Sud, Villejuif, France
To the Editor: The $1 \mathrm{~h}$ post-load plasma glucose (1hPG) measurement has the potential to serve as a sensitive screening tool for identifying people who, despite having normal glucose tolerance (NGT), are at high-risk of developing type 2 diabetes over the next few years $[1,2]$. Screening would be timely, as beta cells are still functional and lifestyle and drug interventions may be effective in delaying diabetes onset.

High $1 \mathrm{hPG}$ has been found to perform as well as the $2 \mathrm{~h}$ post-load plasma glucose ( $2 \mathrm{hPG}$ ) measurement in predicting type 2 diabetes risk after median follow-up times of 9 and 13 years [3]. In a 33 year study, it was not only a better predictor of incident diabetes, but also of diabetes complications and mortality [4]. Robust evidence from the Botnia study and Malmö Prevention Project cohorts supports $1 \mathrm{hPG}$ as the best simple variable predicting incident type 2 diabetes, in comparison with other indices [1].

In a cross-sectional study, we previously described reduced euglycaemic clamp insulin sensitivity and impaired beta cell glucose sensitivity (BCGS) in people with NGT but with high 1hPG in 1205 healthy participants in the European Group for the Study of Insulin Resistance (EGIR) cohort: Relationship between Insulin Sensitivity and Cardiovascular Risk (RISC) [2]. There was a significant decreasing trend in insulin sensitivity from NGT with low $1 \mathrm{hPG}$, to NGT with high $1 \mathrm{hPG}$ to impaired glucose tolerance (IGT: 2hPG: 7.8-11.1 mmol/l); BCGS was significantly higher in those with NGT and low 1hPG, in comparison with NGT and high $1 \mathrm{hPG}$ or IGT. This analysis of NGT included people without IGT and with a fasting plasma glucose (FPG) $<6.1 \mathrm{mmol} / \mathrm{l}$, the WHO definition of impaired fasting glucose (IFG) [2]. In our previous cross-sectional analysis of the baseline population, a $1 \mathrm{hPG}$ of $8.95 \mathrm{mmol} / \mathrm{l}$ was the 'optimal' cut-point (maximising [sensitivity + specificity]) associating $1 \mathrm{hPG}$ with prevalent IGT [2].

We now report 3 year longitudinal data from 797 participants with NGT at baseline, who had complete baseline and 


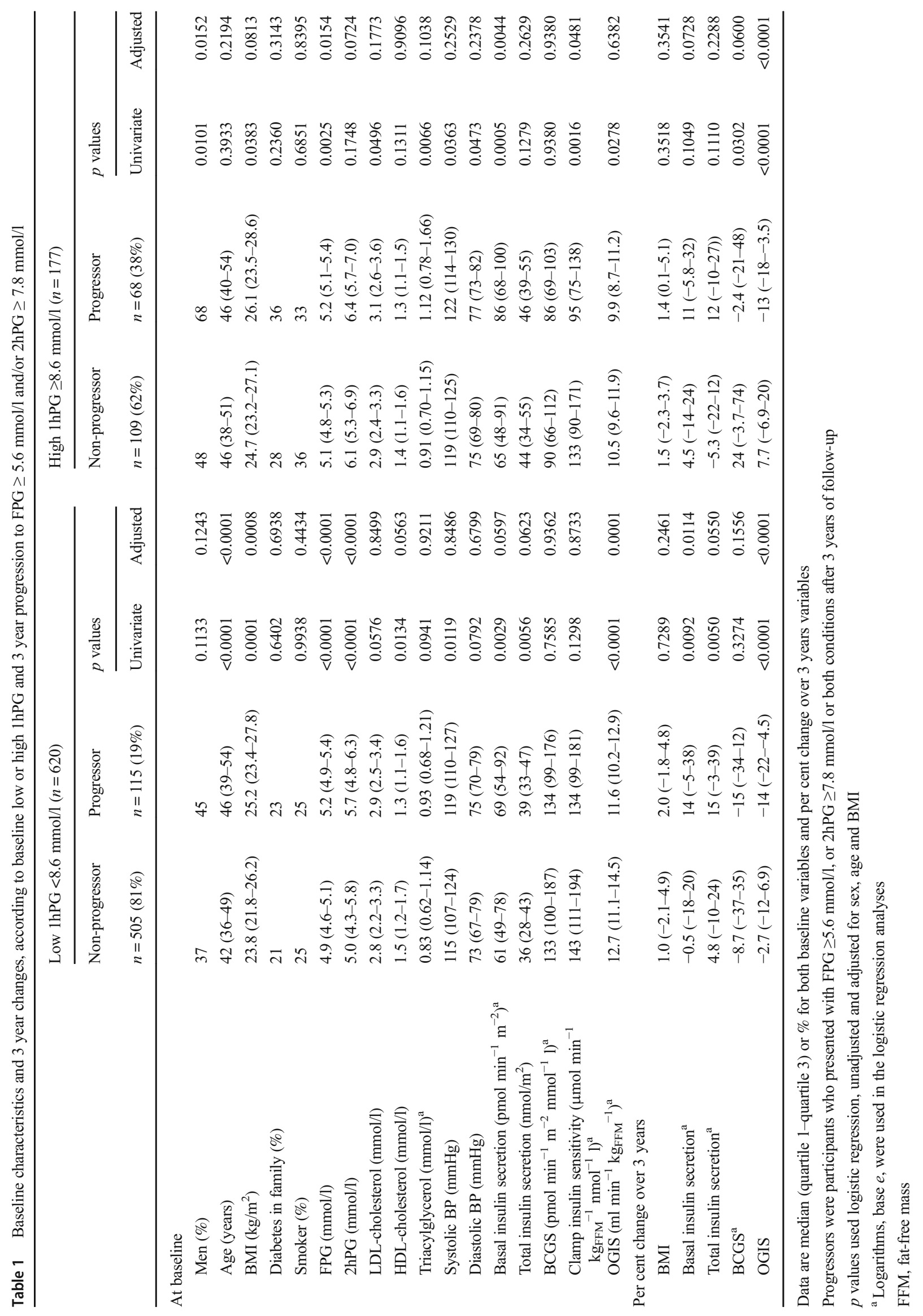


follow-up glucose data (see Table 1). Participants in the RISC study gave written informed consent. Ethics committee approval was obtained in each centre. The study was carried out in accordance with the Declaration of Helsinki as revised in 2008. The RISC Project Management Board approved the present analysis. In the present analysis, the definition of NGT was based on the ADA 2003 criteria (FPG $<5.6 \mathrm{mmol} / \mathrm{l}$ and $2 \mathrm{hPG}<7.8 \mathrm{mmol} / \mathrm{l}$, and not being treated for diabetes). The glucose tolerance status had worsened after 3 years for 183 people (23\%): 40 had normal FPG but IGT; 117 had normal 2hPG but IFG (defined as FPG 5.6-6.9 mmol/1); 26 had both high FPG and 2hPG (including one case of diabetes diagnosed on the basis of FPG, and one on the basis of $2 \mathrm{hPG}$ ). There was a higher percentage of progression to isolated IFG than to isolated IGT ( $15 \%$ vs $5 \%$ ), with $3 \%$ showing progression on both FPG and 2hPG.

In the population currently being studied over 3 years of follow-up, as described in Table 1, the 'optimal' cut-point associated with a worsening glucose status was $7.6 \mathrm{mmol} / \mathrm{l}$, corresponding to 306 (38\%) of our NGT population. After adjusting for sex, age and BMI, the corresponding cut-point was $6.2 \mathrm{mmol} / \mathrm{l}$, corresponding to $526(66 \%)$ of our population. These frequencies of people at risk of diabetes are probably too high for these cut-points to be used in practice. A petition has been published proposing a $1 \mathrm{hPG}$ of $8.6 \mathrm{mmol} / \mathrm{l}$ be used as a cut-point for diagnosing IGT, based on a number of large population based studies [5]; this cut-point identified $177(22 \%)$ in our population.

In the present analysis, the percentage of people whose glucose status progressed according to $1 \mathrm{hPG}$ (electronic supplementary material [ESM] Fig. 1) showed a linear relationthe higher the $1 \mathrm{hPG}$, the higher the percentage that progressed-but there is no clear threshold for defining a cut-point. However, comparing people with a $1 \mathrm{hPG}$ $\geq 8.6 \mathrm{mmol} / \mathrm{l}$ with those below this cut-point, the OR of progression was 2.74 (95\% CI 1.90, 3.95); after adjusting the logistic regression for sex, age and BMI the OR was 2.19 $(1.49,3.20)$ and this remained statistically significant after adjusting for either FPG or $2 \mathrm{hPG}$. The $1 \mathrm{hPG}$ associated with progressing according to either FPG or $2 \mathrm{hPG}$, or both, had a C statistic of 0.67 , and this was not significantly different from those of FPG (0.71) or $2 \mathrm{hPG}(0.65)$, using the DeLong test, in keeping with previous studies $[2,3]$.

In the current group of 797 participants we present, as medians (interquartile range) or $\%$, the metabolic features of individuals with NGT whose glucose status progressed ('progressors') vs those who did not ('non-progressors') according to $1 \mathrm{hPG}(<$ and $\geq 8.6 \mathrm{mmol} / \mathrm{l})$ at baseline (Table 1 ). Comparisons between progressors and non-progressors were made by logistic regression, unadjusted, and adjusted for sex, age and BMI. In progressors from both NGT groups, after adjusting for sex, age and BMI, a higher baseline FPG was the only common statistically significant risk factor; however in the low $1 \mathrm{hPG}$ group, progressors were older, the $2 \mathrm{hPG}$ was higher and the oral glucose insulin sensitivity (OGIS) index [6] was lower in progressors than non-progressors; for the high $1 \mathrm{hPG}$ group, basal insulin secretion was higher and the clamp measure of insulin sensitivity lower in progressors than in non-progressors, indicating the importance of these two factors. Over three years of follow-up, the OGIS index decreased more in progressors in both $1 \mathrm{hPG}$ groups, while in the low $1 \mathrm{hPG}$ group, basal insulin secretion increased more in progressors (Table 1). The sample sizes in our data are not large, particularly for the high $1 \mathrm{hPG}$ group; we can note that over three years the BCGS decreased more in progressors than in non-progressors in the high $1 \mathrm{hPG}$ group $(p=0.0600)$.

More people progressed in relation to an increase in FPG than in $2 \mathrm{hPG}, 143(18 \%)$ vs $66(8 \%)$ (with 26 of these progressing in relation to both), so the metabolic features described in the paragraph above for progressors reflect more the metabolic impairment of participants who developed isolated IFG rather than isolated IGT or combined IFG and IGT; indeed we observed a higher clamp insulin sensitivity for isolated IFG than for isolated IGT, in both 1hPG groups (ESM Tables 1 and 2). In the low 1hPG group, comparing people who progressed to isolated IFG or isolated IGT over three years, basal insulin secretion increased more, total insulin secretion less and OGIS decreased less in those who progressed to isolated IFG; with the small sample sizes in the high $1 \mathrm{hPG}$ group, no statistically significant differences were seen, but changes were in the same direction (ESM Tables 1 and 2).

These new data from the RISC study further support the notion that high $1 \mathrm{hPG}$ is associated with an increased risk of IGT, and also of IFG, and it represents an intermediate risk category between IFG and IGT, supporting the case to rehabilitate the $1 \mathrm{hPG}$ test for use in the prediction of type 2 diabetes risk.

The RISC study provides insight on mechanisms involved in the deterioration of glucose homeostasis in individuals at risk of type 2 diabetes. The balance between insulin secretion and insulin sensitivity is central along the progression pathway to overt diabetes in a continuum of risk. Data from other cohort studies with similar measures are now required to validate our results.

Data availability The RISC data base is open to other researchers for projects approved by the Project Management Board. Requests should be addressed to egir@med.unipi.it.

Funding The RISC study received the European Union Grant QLG1CT-2001-01252 and AstraZeneca, Sweden provided additional finances. Merck, France supported the European Group for the study of Insulin Resistance (EGIR). There has been no funding for the analysis or writing of this article. The study sponsors were not involved in the study design, collection, analysis and interpretation of data, the writing of this report nor in the decision to submit for publication.

Duality of interest The authors declare that there is no duality of interest associated with this manuscript. 
Contribution statement $\mathrm{MM}$ and $\mathrm{BB}$ designed the study, performed the analysis, interpreted the data and drafted the letter. AM contributed to data analysis, data interpretation and revised the manuscript for important intellectual content. BB, GM and JP contributed to data acquisition. GM and JP revised the draft for important intellectual content. All authors approved the final manuscript to be published. $\mathrm{MM}$ and $\mathrm{BB}$ are the guarantors of this work.

\section{Appendix}

\section{EGIR-RISC Investigators}

\section{EGIR-RISC recruiting centres}

Amsterdam, the Netherlands: RJ Heine, J Dekker, S de Rooij, G Nijpels, W Boorsma

Athens, Greece: A Mitrakou, S Tournis, K Kyriakopoulou, P Thomakos

Belgrade, Serbia: N Lalic, K Lalic, A Jotic, L Lukic, M Civcic

Dublin, Ireland: J Nolan, TP Yeow, M Murphy, C DeLong, G Neary, MP Colgan, M Hatunic

Frankfurt, Germany: T Konrad, H Böhles, S Fuellert, F Baer, H Zuchhold

Geneva, Switzerland: A Golay, E Harsch Bobbioni,V Barthassat, V Makoundou, TNO Lehmann, T Merminod Glasgow, Scotland, UK: JR Petrie, C Perry, F Neary, C MacDougall, K Shields, L Malcolm

Kuopio, Finland: M Laakso, U Salmenniemi, A Aura, R Raisanen, U Ruotsalainen, T Sistonen, M Laitinen, $\mathrm{H}$ Saloranta

London, England, UK: SW Coppack, N McIntosh, J Ross, L Pettersson, P Khadobaksh

Lyon, France: M Laville, F Bonnet (now Rennes), A Brac de la Perriere, C Louche-Pelissier, C Maitrepierre, J Peyrat, S Beltran, A Serusclat

Madrid, Spain: R Gabriel, EM Sánchez, R Carraro, A Friera, B Novella

Malmö, Sweden (1): P Nilsson, M Persson, G Östling, (2): O Melander, P Burri

Milan, Italy: PM Piatti, LD Monti, E Setola, E Galluccio, F Minicucci, A Colleluori

Newcastle-upon-Tyne, England, UK: M Walker, IM Ibrahim, M Jayapaul, D Carman, C Ryan, K Short, Y McGrady, D Richardson

Odense, Denmark: H Beck-Nielsen, P Staehr, K Højlund, V Vestergaard, C Olsen, L Hansen

Perugia, Italy: GB Bolli, F Porcellati, C Fanelli, P Lucidi, F Calcinaro, A Saturni

Pisa, Italy: E Ferrannini, A Natali, E Muscelli, S Pinnola, M Kozakova, A Casolaro, BD Astiarraga

Rome, Italy: G Mingrone, C Guidone, A Favuzzi, P Di Rocco Vienna, Austria: C Anderwald, M Bischof, M Promintzer, M Krebs, M Mandl, A Hofer, A Luger, W Waldhäusl, M Roden
Project Management Board: B Balkau (Villejuif, France), F Bonnet (Rennes, France), SW Coppack (London, England, UK), JM Dekker (Amsterdam, the Netherlands), E Ferrannini (Pisa, Italy), A Mari (Padova, Italy), A Natali (Pisa, Italy), J Petrie (Glasgow, Scotland, UK), M Walker (Newcastle, England, UK)

\section{Core laboratories and reading centres}

Lipids: Dublin, Ireland: P Gaffney, J Nolan, G Boran Hormones: Odense, Denmark: C Olsen, L Hansen, H BeckNielsen

Albumin:creatinine: Amsterdam, the Netherlands: A Kok, J Dekker

Genetics: Newcastle-upon-Tyne, England, UK: S Patel, M Walker

Stable isotope laboratory: Pisa, Italy: A Gastaldelli, D Ciociaro

Ultrasound reading centre: Pisa, Italy: M Kozakova

ECG reading: Villejuif, France: MT Guillanneuf Actigraph: Villejuif, France: B Balkau, L Mhamdi

Data Management: Villejuif, France, Padova, and Pisa, Italy: B Balkau, A Mari, L Mhamdi, L Landucci, S Hills, L Mota

Mathematical modelling and website management: Padova, Italy: A Mari, G Pacini, C Cavaggion, A Tura

Coordinating office: Pisa, Italy: SA Hills, L Landucci, L Mota

Further information on the EGIR-RISC study and participating centres can be found on www.egir.org.

Open Access This article is distributed under the terms of the Creative Commons Attribution 4.0 International License (http:// creativecommons.org/licenses/by/4.0/), which permits unrestricted use, distribution, and reproduction in any medium, provided you give appropriate credit to the original author(s) and the source, provide a link to the Creative Commons license, and indicate if changes were made.

Publisher's note Springer Nature remains neutral with regard to jurisdictional claims in published maps and institutional affiliations.

\section{References}

1. Alyass A, Almgren P, Akerlund M et al (2015) Modelling of OGTT curve identifies $1 \mathrm{~h}$ plasma glucose level as a strong predictor of incident type 2 diabetes: results from two prospective cohorts. Diabetologia 58(1):87-97. https://doi.org/10.1007/s00125-0143390-x

2. Manco M, Panunzi S, Macfarlane DP et al (2010) One-hour plasma glucose identifies insulin resistance and beta-cell dysfunction in individuals with normal glucose tolerance: cross-sectional data from the Relationship between Insulin Sensitivity and Cardiovascular Risk (RISC) study. Diabetes Care 33(9):2090-2107. https://doi.org/ $10.2337 / \mathrm{dc} 09-2261$ 
3. Paddock E, Hohenadel MG, Piaggi P et al (2017) One-hour and twohour postload plasma glucose concentrations are comparable predictors of type 2 diabetes mellitus in Southwestern Native Americans. Diabetologia 60(9):1704-1711. https://doi.org/10.1007/s00125-0174332-1

4. Pareek M, Bhatt DL, Nielsen ML et al (2018) Enhanced predictive capability of a 1-hour oral glucose tolerance test: a prospective population-based cohort study. Diabetes Care 41(1):171-177. https://doi.org/10.2337/dc17-1351
5. Bergman M, Manco M, Sesti G et al (2018) Petition to replace current OGTT criteria for diagnosing prediabetes with the 1-hour postload glucose $\geq 155 \mathrm{mg} / \mathrm{dl}$ (8.6 mmol/l). Diab Res Clin Pract 146:1833. https://doi.org/10.1016/j.diabres.2018.09.017

6. Mari A, Pacini G, Murphy E, Ludvik B, Nolan JJ (2001) A modelbased method for assessing insulin sensitivity from the oral glucose tolerance test. Diabetes Care 24(3):539-548. https://doi.org/10.2337/ diacare.24.3.539 